\title{
Gender: Does it have role has a role in glycaemic control and diabetic distress in type 2 diabetes?
}

\author{
Sasisekhar T.V.D ${ }^{1}$, Shabana $\mathrm{S}^{2}$, Sirisha. $\mathrm{Y}^{3}{ }^{3}$ Bhargav $^{4}$ \\ 1Assoc Prof, Department of medicine, Dr.PSIMS \& RF Chinna Avutapalli, Vijayawada, Andhra Pradesh \\ 2Assoc Professor of Biochemistry, Dr. PSIMS \& RF, Chinna Avutapalli, Vijayawada, Andhra Pradesh \\ 3Post graduate, Department of medicine, Dr.PSIMS \& RF Chinna Avutapalli, Vijayawada, Andhra Pradesh \\ 4Resident, Department of medicine, Dr.PSIMS \& RF Chinna Avutapalli, Vijayawada, Andhra Pradesh
}

\begin{abstract}
Diabetes mellitus is a global epidemic with rapidly rising incidence all over the world. There is clear evidence of effect of obesity, exercise, drug adherence, and presence of comorbid conditions, on level of diabetic control. But there is no clear data regarding effect of gender on glycemic control, with conflicting data from different studies. In India, in particular, there are very few such studies till date. Literature suggests that diabetic control depends on various variables and that younger patients, women, and those with comorbidities require particular clinical attention to reduce diabetic-distress and its negative impact on prognosis. Our study aims at comparing differences in glycemic control between men and women with emphasis on diabetes distress in each gender.

Method - A systematic random sample (every third patient) of 360 patients was selected from all patients with type 2 diabetes who attended our general hospital over a period of 6 months in 2012. Informed verbal consent was taken from participants. Ethical clearance was obtained in prior. Personal interview regarding variables with respect to the disease was held. The patients were assessed for glycemic control (HbAlc) and diabetes distress.

Results - 55\% males and 67\% females had significant diabetic distress, the difference in distress between both sexes was found to be statistically significant $(p=0.0233)$. $45 \%$ males and $58 \%$ females had poor glycaemic control. the difference between two genders with regard to poor glycaemic control was found statistically significant ( $p=0.0197 \%)$.

Conclusions - Diabetes is considered a social stigma for females in rural India which make them have low awareness about their disease, its complications, adherence to medication and other self care practices. This may contribute to poor glycemic control, which highlights the need for health education
\end{abstract}

Key words: Diabetes mellitus; Glycemic control; HbAlc, diabetes distress

\section{Introduction}

Type 2 diabetes is a global public health crisis that threatens the economies of all nations, particularly developing countries [1]. In recent decades, Asia has undergone rapid economic development, urbanization, and transitions in nutritional status (2). These have led to an explosive increase in diabetes prevalence within a relatively short time. In urban areas of south India, the prevalence of diabetes has reached nearly $20 \%$ (3).

Management of this vast number of diabetic patients poses a medical social and economic burden on our country. A clear understanding of the factors influencing the control of hyperglycaemia is essential in planning and implementing diabetic control programmes.

There is clear evidence of effect of obesity, exercise, lack of drug adherence, duration of diabetes and the presence of comorbid conditions on the level of diabetic control [4]. Clinical depression, anxiety disorders, depressive affect and diabetes-specific distress are common conditions in patients with diabetes, and all have been linked with a variety of bio-behavioural variables and poor disease management [5]. Gender differences in reported mood and relationships between comorbidities and anxiety are also found in the literature [6]. Studies also report the effect of gender on glycemic control but with conflicting data on gender equity[7,8,9].

Our study aims at comparing the differences in levels of control of hyperglycaemia between men and women with emphasis on diabetes distress in each gender.

\section{Material and methods}

A systematic random sample (every third patient) of 360 patients after taking verbal consent were selected from all patients with Type 2 diabetes who attended Dr Pinnamaneni Siddhartha Institute of Medical Sciences and Research Foundation, Chinna avutapalli, Vijayawada over a period of 6 months in 2012. Participants were informed about the objective of the study.

This study was approved by the institutional ethical committee. Personal interview was held to collect data including age, gender, BMI etc. Subjects in the age group of 30 - 60 years, with a history of type 2 diabetes, 
who were on OHA, insulin or both and subjects with history of any systemic illnesses were included in the study. Pregnant women and those on drugs and that may affect the blood glucose levels and thus glycosylated hemoglobin like corticosteroids, oral contraceptives, thiazides diuretics, ascorbic acid, quinolones, beta blockers were excluded from the study. The subjects were assessed for diabetes distress using a diabetes distress scale (DDS) and a mean item score was calculated. Glycosylated haemoglobin (HbA1c) was taken as an index of glycemic control and analyzed by randox kits on randox (Daytona) analyzer.

Statistical analysis was done using graph pad prism 6 version. Fischer's and chi square test was used to know the relationship between variables. $\mathrm{P}$ value less than 0.05 was considered as statically significant.

\section{Operational definitions}

$\mathrm{HbA} 1 \mathrm{c}<7 \%$ is considered good glycemic control, while a HbA1c $>7 \%$ was considered as poor glycemic control [10]

The Diabetes Distress Scale (DDS17) yields a total diabetes distress scale score plus 4 sub scale scores, each addressing a different kind of distress. A mean item score of 3 or higher is considered as a level of distress worthy of clinical attention [11].

BMI greater than 25 was considered as overweight [12]

\section{Results}

Out of a total of 360 subjects 160 were females and 200 were male diabetics. The demographic characteristics of the subjects are shown in Table 1. Male study population were (56\%) when compared to female population (44\%). About (58\%) of the study population were above the age group of 55 years while 57\% of the study participants had Body Mass Index $>25$. More number of the study population $56 \%$ were on oral hypoglycemic drugs followed by $26 \%$ on insulin.

Table 2 shows the relationship between gender, BMI and HbA1c. Males had better glycemic control when compared to females. Statistically significant difference $(\mathrm{p}=0.019)$ was found in between 2 genders with regard to HbA1c. Subjects (male \&female) with BMI more than 25 had statistically significant poor glycemic control when compared to those with BMI less than 25. Similar effect was found when male and females were analysed individually.

Table 3 deals with relationship between gender, age and diabetes distress. In our study, more females (66\%) have diabetes distress compared to males (35\%).There was statically significance difference in distress between both sexes ( $\mathrm{p}=0.0233$ ). When diabetes distress was compared between age below 55 yrs and age above $55 \mathrm{yrs}$, there was no significant relationship between two aged groups $(\mathrm{p}=0.3655)$ in males. Females below 55 years had statistically significant $(\mathrm{p}=0.024)$ diabetic distress compared to females below 55 years.

\section{Discussion}

It has been shown that glycemic control can lower the risk of long term complications [13,14].In our study the data shows that there are more number of diabetics with BMI $>25$ and more number of the subjects are on oral hypoglycaemic agents. Comparison of BMI $<25$ and $>25$ against a $\mathrm{HbAlc}>7 \%$ and $<7 \%$ was statistically significant in both male diabetics female diabetics. These findings are in corroboration with other studies [15]. The links between type 2 diabetes and obesity are firmly established. According to a survey by the Centers for Disease Control and Prevention [16], the prevalence of obesity among persons diagnosed with diabetes was 53\% in men and 58\% in women. Even higher percentages were classified as overweight $-86.3 \%$ in men and $84.2 \%$ in women. Obesity imposes significant costs to the health-care system, much of which are borne by the public sector [17]. An analysis of drug spending for community-dwelling Medicare beneficiaries found that for seven common disorders, drug spending increased with BMI; for those with diabetes, annual drug spending more than doubled as BMI increased from $<18.5$ to $>35.0$. Overall medical spending for obese individuals is approximately $40 \%$ higher than for those of normal weight [18].

Diabetic distress was found to be being highest in younger women and lowest in older men, [19]. A similar finding was noted in our study which gender wise showed a significant difference in the mean diabetic score, with a greater percentage of female diabetics with a mean diabetic distress score $>3$. By age, no significant difference was noted in the mean diabetic distress score in males while female diabetics less than 55 years showed a significant difference. Female gender was observed to be linked to persistence of depressive symptoms, diabetes distress and PANIC [20]. Psychosocial attributes, most notably diabetes-related emotional distress, contribute to difficulty with diabetes self-management, poor glycemic control, and worsening diabetes status over time.

As noted by another study good glycaemic control was significantly associated with older age, higher education, higher patient activation, lower diabetes-related emotional distress, better diet and exercise behaviours, lower body mass index, shorter duration of disease and knowledge of $\mathrm{HbA}(1 \mathrm{c})$ targets [21]. 
Gender: Does it have role has a role in glycaemic control and diabetic distress in type 2 diabetes?

There is a relationship between achievements in glycemic control and subsequent lowering of diabetic stress. In addition, it was associated with glycemic and obesity indices. Obese subjects often have suboptimal quality of life $(22,23)$, probably because of the long-term struggle to lose or maintain body weight. There are close linkages between mental stress and activation of the stress hormonal systems, notably the hypothalamicpituitary-adrenal axis, which can set up a vicious cycle of stress and obesity (24).

These findings suggest that younger patients, women and those with many comorbidities may require particular clinical attention to reduce distress and its negative impact on diabetes outcomes. Women may need additional support and specialized programs for encouragement and of self-management behaviors, problem solving, and addressing gender-specific barriers to self [25].

\section{Tables}

Table 1 Demographic profile

\begin{tabular}{|l|l|l|l|}
\hline Variable & & Number & $\%$ \\
\hline \multirow{2}{*}{ Sex } & Males & 160 & 44 \\
\cline { 2 - 4 } & Females & 200 & 56 \\
\hline \multirow{3}{*}{ Age } & $\leq 55$ & 150 & 42 \\
\cline { 2 - 4 } & $>55$ & 210 & 58 \\
\hline \multirow{3}{*}{ BMI } & $<25$ & 154 & 43 \\
\cline { 2 - 4 } & $>25$ & 206 & 57 \\
\hline \multirow{3}{*}{ Treatment } & Insulin & 138 & 38 \\
\cline { 2 - 4 } & OHA & 202 & 56 \\
\cline { 2 - 4 } & OHA,Insulin & 20 & 6 \\
\hline
\end{tabular}

Table 2 Effect of gender and BMI on HbA1c

\begin{tabular}{|c|c|c|c|c|}
\hline Variable & & HbA1c $<7$ & HbA1c $>7$ & $P$ value \\
\hline \multirow{2}{*}{ Sex } & Males & $109(55 \%)$ & $91(45 \%)$ & \multirow{2}{*}{0.0197} \\
\hline & Females & $67(42 \%)$ & $93(58 \%)$ & \\
\hline \multirow{2}{*}{$\begin{array}{l}\text { BMI (in total } \\
\text { population) }\end{array}$} & $<25$ & $95(55 \%)$ & $78(45 \%)$ & \multirow{2}{*}{0.0347} \\
\hline & $>25$ & $81(43 \%)$ & $106(57 \%)$ & \\
\hline \multirow{2}{*}{ BMI (in males) } & $<25$ & $60(63 \%)$ & $35(37 \%)$ & \multirow{2}{*}{0.0231} \\
\hline & $>25$ & $49(46 \%)$ & $56(54 \%)$ & \\
\hline \multirow{2}{*}{$\begin{array}{l}\text { BMI (in } \\
\text { females) }\end{array}$} & $<25$ & $41(52 \%)$ & $37(48 \%)$ & \multirow[t]{2}{*}{0.0102} \\
\hline & $>25$ & $26(32 \%)$ & $56(68 \%)$ & \\
\hline
\end{tabular}

Data represented as number with percentage in parentheses

Statistically significant $-\mathrm{p}$ value $<0.05$

Table 3 Effect of gender and age on diabetes distress

\begin{tabular}{|c|c|c|c|c|}
\hline Variable & & DDS $<3$ & DDS > 3 & $P$ value \\
\hline \multirow{2}{*}{ Sex } & Males & $90(45 \%)$ & $110(55 \%)$ & \multirow{2}{*}{0.0233} \\
\hline & Females & $53(33 \%)$ & $107(67 \%)$ & \\
\hline \multirow{2}{*}{ Age (in total population) } & $<55$ & $56(37 \%)$ & $94(63 \%)$ & \multirow{2}{*}{0.4465} \\
\hline & $>55$ & $87(41 \%)$ & $123(59 \%)$ & \\
\hline \multirow{2}{*}{ Age (in males) } & $<55$ & $30(43 \%)$ & $40(57 \%)$ & \multirow{2}{*}{0.3655} \\
\hline & $>55$ & $48(36 \%)$ & $85(64 \%)$ & \\
\hline \multirow{2}{*}{ Age (in females) } & $<55$ & $26(32 \%)$ & $54(68 \%)$ & \multirow{2}{*}{0.0240} \\
\hline & $>55$ & $39(51 \%)$ & $38(49 \%)$ & \\
\hline
\end{tabular}

Data represented as number with percentage in parentheses

Statistically significant $-\mathrm{p}$ value $<0.05$

\section{Conclusion}

Gender differences in the clinical manifestations and consequences of diabetes may reasonably lead to differences in both the need for and use of health services. It is important for the diabetes educator to address obesity as a comorbidity to diabetes and as a part of diabetes self-management and behavior change. Self- 
management and adherence interventions should target psychosocial attributes such as disease-related emotional distress.

\section{References:}

[1] Frank B. Hu, MD, PHD Globalization of Diabetes The role of diet, lifestyle, and genes. Diabetes Care June 2011 vol. 34 no. 6 1249-1257

[2] Chan JC, Malik V, Jia W, et al Diabetes in Asia: epidemiology, risk factors, and pathophysiology. JAMA 2009;301:2129-2140

[3] Ramachandran A, Mary S, Yamuna A, Murugesan N, Snehalatha C. High prevalence of diabetes and cardiovascular risk factors associated with urbanization in India. Diabetes Care 2008;31:893-898

[4] Maysaa Khattaba, Yousef S. Khaderb C, Abdelkarim Al-Khawaldehd, Kamel AjlounidFactors associated with poor glycemic control among patients with Type 2 diabetes.. Journal of Diabetes and Its Complications 24 (2010) 84-89

[5] Ciechanowski PS, Katon WJ, Russo JE. Depression and diabetes: impact of depressive symptoms on adherence, function, and costs. Arch Intern Med. 2000;160:3278-3285

[6] Scott KM, Bruffaerts R, Tsang A, Ormel J, Alonso J, Angermeyer MC, et al. Depression- anxiety relationships with chronic physical conditions: results from the World Mental Health Surveys. J Affect Disord. 2007;103:113-120

[7] Power F and Snoek FJ. Association between symptoms of depression and glycaemic control may be unstable across gender. Diabetic Med 2001;18: 595-598

[8] Kobayashi J, Maruyama T, Watanabe H, et al. Gender differences in the effect of type 2 diabetes on serum lipids, pre-heparin lipoprotein lipase mass and other metabolic parameters in Japanese population. Diabetes Res and Clin Pract 2003; 62:39-45

[9] Pomerleau J, McKeigue PM and Chaturvedi N. Relationships of fasting and postload glucose levels to sex and alcohol consumption. Diabetes Care 1999; 22:430-433

[10] Position statement, Standards of Medical Care in Diabetes-2012, Diabetes Care, 35 (1), 2012, S11-S63

[11] Lawrence Fisher, Russell E. Glasgow,Joseph T. Mullan, Marilyn M. Skaff, William H. Polonsky. Development of a Brief Diabetes Distress Screening Instrument. Ann Fam Med 2008;6:246-252

[12] World Health Organization. (1995). Physical status: The use and interpretation of anthropometry: Report of a WHO Expert committee. Technical report series 854. Geneva

[13] Saaddine, J. B., Cadwell, B., Gregg, E. W., et al. (2006). Improvements in diabetes processes of care and intermediate outcomes: United States, 1988-2002. Annals of Internal Medicine, 144(7), 465-474

[14] UK Prospective Diabetes Study (UKPDS) Group. (1998). Intensive blood glucose control with sulphanylureas or insulin compared with conventional treatment and risk of complications in patients with Type 2 diabetes. Lancet, 352, 837-853

[15] Imad M, Curtis B, David C, et al. association of younger age with poor glycemic control and obesity in urban African Americans with type 2 diabetes. Arch Intern Med. 2003; 163:69-75

[16] Centers for Disease Control and Prevention. Prevalence of overweight and obesity among adults with diagnosed diabetes - United States, 1988 - 1994 and 1999 - 2002. MMWR Morb Mortal Weekly Rep 2004;53(45):1066-1068

[17] Finkelstein EA, Trogdon JG, Cohen JW, Dietz W. Annual medical spending attributable to obesity: payer and service estimates. Health Affairs 2009;28(5)w822-w831.

[18] Stuart B, Lloyd J, Zhaao L, Kaman-Bahl S. Obesity, disease burden, and prescription spending by community-dwelling Medicare beneficiaries. Curr Med Res Opin2008;24(8):2377-2387

[19] Sayed Aamir, Sallie Areford, Matthew Hix, Ali Rizvi. Relationship of Age and Gender to "Diabetes Distress" and Postprandial Hyperglycemia: Impact of a Multidisciplinary Supportive, Dietary, and Pharmacologic Approach. Middle east journal of psychiatry and alzheimers, volume 3 , issue 3

[20] L. Fisher, M. M. Skaff, J. T. Mullan, P. Arean, R. Glasgow, and U. MasharaniA longitudinal study of affective and anxiety disorders, depressive affect and diabetes distress in adults with Type 2 diabetes Diabet Med. 2008 September; 25(9): 1096-1101

[21] Rogvi S, Tapager I, Almdal TP, Schiøtz ML, Willaing I. Patient factors and glycaemic control--associations and explanatory power. Diabet Med. 2012;29(10) e382-9.[22]Katz DA, McHorney CA, Atkinson RL. Impact of obesity on health-related quality of life in patients with chronic illness. J Gen Intern Med 2000;15:789-796

[23] Hlatky MA, Chung SC, Escobedo J, et al.; BARI 2D Study Group. The effect of obesity on quality of life in patients with diabetes and coronary artery disease. Am Heart J 2010;159:292-300

[24] Kong AP, Chan NN, Chan JC. The role of adipocytokines and neurohormonal dysregulation in metabolic syndrome. Curr Diabetes Rev 2006;2:397-407

[25] R Misra, J Lager Ethnic and gender differences in psychosocial factors, glycemic control, and quality of life among adult type 2 diabetic patients Journal of Diabetes and its Complications, 2009 - Elsevier 